gas equipment are first considered, there is then a paper on batch and continuous annealing of copper and copper alloys, one on the bright annealing of nickel and its alloys, and finally three papers on the batch treatment, flash annealing and continuous heat-treatment of the alloys of aluminium. Twentynine plates give a very clear idea of the type of equipment which has been designed and used. The papers, however, are no mere description of plant and apparatus, this being linked to the underlying mechanical and metallographic changes which the treatments are desired to effect. The importance of the atmosphere in which the heating is carried out is emphasized in more than one of the communications, and in that on the bright annealing of nickel and its alloys is discussed in some detail. The utility of the papers is further enhanced by the discussion which resulted, and the whole forms a contribution to the subject of real importance.

(4) In some ways the fourth of these monographs is the most outstanding. In February 1952 a symposium was held on the nature of molten slags and salts by the Nuffield Research Group in Extraction Metallurgy, which is working at the Royal School of Mines, London, on the reactions of systems connected with the winning and refining of metals. Two papers deal with the constitution of liquid oxides and silicates; anomalies in the surface tension of silicates are then considered ; and three other papers deal with the correlation between activity and composition in mixtures of fused salts, heats of mixing in the liquid ferrous oxide-silica system and the thermodynamic aspects of molten slags. Each of these presents a clear picture of the present state of knowledge, and it will perhaps surprise many readers to find how wide this already is. To those who are in any way concerned with the physical chemistry of molten salgs and salte, this little book may be most strongly recommended.

F. C. Tномrson

\section{INORGANIC CHEMISTRY FOR THE GENERAL STUDENT}

General and Inorganic Chemistry

By Dr. P. J. Durrant. Second edition. Pp. $x+671$. (London, New York and Toronto: Longmans, Green and Co., Ltd., 1952.) 21s.

Reference Book of Inorganic Chemistry

By Prof. Wendell M. Latimer and Prof. Joel H. Hildebrand. Third edition. Pp. xiii +625 . (New York : The Macmillan Company; London: Macmillän and Co., Ltd., 1952.) $37 s .6 d$. net.

\footnotetext{
A $T$ a time when the supply of scientific workers $A$ and technologists is of national importance in Britain, it is a matter of some concern to consider their early training, so often provided in the sixth forms of schools. The teacher at this stage has the heavy responsibility of laying firmly and wisely the foundations of the sciences, while at the same time encouraging interest and enthusiasm in a particular science, frequently chemistry. To achieve this in a rapidly advancing subject such as chemistry, the methods of presentation must be constantly under review. The teacher has available to aid him in this several excellent text-books, constantly under revision, which are known affectionately by the names of their authors. "Durrant" is one of these, now appearing in a second edition.
}

The new edition has several modifications and additions, including a completely revised chapter on valency, atomic structure and the periodic table, which now introduces the numerical concept of electro-negativity as well as the qualitative treatment afforded by Fajan's rules. The importance of ions in the understanding of a great deal of 'elementary' chemistry is emphasized by revision of the chapters dealing with electrolytes, electrode potentials and electrolysis. The treatment given to the electrochemical series and to electrode potentials will be of particular value to teachers. New chapters have been added to cover colloids and nuclear chemistry (including nuclear and thermo-nuclear energy). A treatment of colloids forms an essential part of any elementary course intended to introduce the student to the chemistry of the world about him, and its inclusion is thus to be especially welcomed. In some measure the same may be said of 'nuclear chemistry' in this atomic age.

A modified form of the periodic table due to Prof. T. S. Wheeler is used in which the $A$ and $B$ subgroups of the short table are re-styled $N$ and $T$ (normal and transition) sub-groups. Some will find its use advantageous ; but it seems to me that the subject is at such a stage of development that the fow advantages of the short form should be shelved in favour of the exclusive use of the more open and obvious long form.

The book is well prepared, and there are only a few trifling mistakes. On a point of nomenclature it is unfortunate that the author should have deviated from what has become established practice in referring to the 'actinides' as 'uranides'. A particularly attractive feature of the book is the large number of questions (401) covering a very wide range of sources. This text-book will continue to play an important part in the teaching of 'elemen. tary' chemistry, and the revised second edition is to be highly recommended both for school and university work.

The third edition of the "Reference Book of Inorganic Chemistry", by Profs. W. M. Latimer and J. H. Hildebrand, is not intended primarily as a text-book, but can be adapted by the teachers to suit their own particular requirements and thereby provide the elementary student with a book containing a wealth of facts arranged and rationalized mainly in terms of the atomic structures and fundamental properties of the elements. As a reference book its value may appear doubtful because of its size, which is very small compared with the better-known reference books of inorganic chemistry. However, there has been a most skilful selection of facts, and there is a surprising amount of material contained within the $\mathbf{5 1 1}$ pages of text and the 86 pages of glossary and appendix. Much of the information in the text is summarized in tables setting out data for particular groups of elements or compounds. The appendix includes a large collection of useful data (notably a table of the m.p., b.p., density, etc., for around 1,300 inorganic substances). This third edition is con. siderably revised from the second edition (1940), and includes a new chapter on nuclear reactions and the actinide elements. It is unlikely to find any great use in Britain as a text-book, since more suitable works are available; but as a handy source of simple facts or data of inorganic chemistry it will be a decidedly useful volume to have on the bookshelf.
D. S. PAYNE 